\title{
LA LESION SUPRAINIANA EN MESOAMÉRICA: IMPLICACIONES ARQUEOLOGICAS
}

\author{
Por Carlos Serrano S. \\ Centro de Estudios Mayas, UNAM \\ Departamento de Antropología Física, INAH
}

\section{Introducción}

Al realizar el examen osteológico del esqueleto correspondiente al entierro número 1 de Palenque, Chiapas, recuperado durante las excavaciones arqueológicas de la temporada de 1970, efectuamos algunas observaciones de interés que han dado base a la presente nota.

Los restos del esqueleto estudiado se encuentran en la Sección de Antropología Física del Museo Nacional de Antropología ${ }^{1}$ y fueron entregados por el arqueólogo Jorge R. Acosta, quien dirigió la excavación en el sitio. El esqueleto fue encontrado asociado a una estructura arqueológica, en posición flexionada. Según su descubridor, este entierro se ubica cronológicamente en el horizonte Posclásico Temprano, aunque podría ser un poco anterior, de fines del Clásico (siglos IX-XI d. C.).

Las características de dicho esqueleto ${ }^{2}$ indican que se trata de los restos de un individuo adulto maduro ( $35-55$ años), de sexo masculino, de una robustez media, a juzgar por la apariencia de los huesos, y con una estatura calculada de $158.7 \mathrm{~cm}$, según las fórmulas de Pearson, o de $157.5 \mathrm{~cm}$ si se aplican las fórmulas de Genovés, establecidas para poblaciones prehispánicas mesoamericanas. De todas maneras se trata de un individuo de talla pequeña, que encajaría perfectamente en la variación de estatura reportada para las poblaciones mayas actuales (Comas, 1966, p. 16).

Entre las características osteopatológicas del esqueleto se cuentan: osteartritis poliarticular, que afectó principalmente la columna vertebral y la articulación témporo-mandibular, una lesión osteomielítica

${ }^{2}$ Hoy Departamento de Antropología Física del INAH.

2 "El entierro núm. 1 de Palenque, Chis. (temporada 1970)". Informe inédito. 
severa en los huesos de las extremidades inferiores (fémur derecho y ambas tibias), caries dental e inflamación del tejido periodontal de ambas arcadas alveolares, elementos que hablan de un pobre estado de salud del sujeto en vida.

En los restos craneales del esqueleto estudiado se pudo apreciar la existencia de una ligera deformación intencional del tipo tabular erecto. El occipital está ligeramente aplanado, en tanto que la bóveda presenta una constricción poscoronal que va de temporal a temporal, paralelamente a la sutura frontoparietal. Se trata seguramente de la huella dejada por la banda sujetadora del aparato deformador, producida al ejercer presión sobre el hueso inmaduro. Poseemos muchos ejemplares craneanos artificialmente deformados que presentan tal característica.

Un dato osteológico de gran interés, por las razones que se mencionarán más adelante, es la presencia de una lesión que se localiza sobre el occipital, en la región iniaca. Se presenta como una depresión bien definida, de forma aproximadamente triangular, con dimensiones de $22 \times 25 \mathrm{~mm}$ (lámina $\mathrm{I}$ ). La superficie ósea que constituye el fondo de dicha depresión muestra huellas de reacción perióstica. Sus características recuerdan grandemente las lesiones suprainianas observadas en cráneos peruanos (Weiss, 1958) y halladas recientemente con gran frecuencia en cráneos mexicanos del Altiplano, en especial de Cholula, Puebla (Lagunas, 1970). La naturaleza y el significado arqueológico de estas lesiones serán discutidos en seguida.

\section{Naturaleza de la lesión suprainiana}

Estas lesiones han sido estudiadas en el Perú por el doctor Pedro Weiss (1958), quien las denominó "trepanaciones suprainianas", considerándolas como intervenciones intencionales sobre la cabeza. Las agrupa, por este motivo, con otros tipos de trepanación, práctica que con diversas técnicas, estuvo bastante difundida en esa región geográfica.

Una característica importante de estas trepanaciones es que se presentan constantemente con una definida localización anatómica, en ambos sexos y en diferentes edades. Según Lagunas (1970, p. 3), quien la ha estudiado en la amplia colección de cráneos de Cholula, Puebla:

la lesión aludida está caracterizada por tener una localización fija en la región occipital, ligeramente por encima del inion, 
delimitada en su parte inferior por la protuberancia occipital externa y las líneas curvas occipitales superiores, que en la mayoría de los sujetos acentúan y modifican su forma, las lesiones varían en cuanto a su forma y magnitud, tanto que en algunos ejemplares es difícil reconocerla, pues se reduce a una ligera depresión digital y en otros a simples rugosidades del hueso; varía también en lo referente al espesor del tejido óseo en esa región, caracterizándose en la mayoría de los casos por su poco espesor; de dos a cuatro milímetros.

La intervención se realizaba aplicando la técnica del raspado que, como se ha mencionado, podía ser desde un raspado ligero del hueso, interesando únicamente la tabla externa, hasta la perforación completa. Se han encontrado casos en que el individuo no sobrevivió mucho tiempo a la operación - la regeneración ósea apenas se iniciaba- y otros más en que la lesión se encuentra casi completamente cicatrizada. En el cráneo de Palenque que motivó este trabajo, no es posible establecer si el raspado del hueso sólo afectó la tabla externa o fue más profundo, debido a una rotura posmortem en el área de la lesión.

Weiss ha mostrado que se trata efectivamente de una intervención quirúrgica (al menos en los casos en que la lesión está bien marcada), y no de un rasgo patológico de otra índole, ni de la huella del dispositivo deformador en los casos de los cráneos artificialmente deformados. Ha identificado la lesión en momias, en las que, sobre la lesión ósea encuentra placas de piel atrófica, translúcida y estrías cicatriciales $(1958$, p. 541). Por otra parte, algunos cráneos no deformados presentaban el mismo tipo de lesión.

El elevado porcentaje de la lesión suprainiana en algunos cementerios peruanos ( $45 \%$ de los cráneos de La Calera, Chancay), su localización en el mismo lugar de la cabeza, su presencia ya cicatrizada en cráneos infantiles y la variación en la intensidad del raspado óseo - predominan los casos en que el operador se limitó a cortar los tejidos blandos y raspar ligeramente el hueso- llevaron al citado investigador a afirmar que se trató de una práctica de rutina en la pediatría de algunas épocas, pero de una práctica no derivada de una necesidad individual de orden terapéutico, como es lo más probable en el caso de las trepanaciones asociadas a hundimientos o heridas traumáticas, sino más bien de un rito o una operación profiláctica, de tipo preventivo, más que curativo (1958, p. 545). Cita Weiss a este respecto, las trepanaciones profilácticas que se realizan en Oceanía: 
En Melanesia, lugar donde la práctica de la trepanación estuvo muy generalizada, particularmente en las comunidades que antes de la influencia europea usaban la honda y la porra como armas de combate, se ha visto que en primer lugar se trepanaba como medida descompresiva o inmediata a las lesiones traumáticas craneales, después como panacea de los males de cabeza: dolores, vértigos, epilepsia y por último, en los niños como profilaxia de todas estas afecciones. Los extraordinarios resultados obtenidos en el primer grupo de indicaciones, decidieron a los curanderos a extenderlo al segundo y de ahí al otro (Parkinson, R., 1907, cit. por Weiss, 1958, p. 546 y Ackerknecht, 1967, p. 643).

Un concepto semejante encontramos en Ford (1937, cit. por Stewart, 1957, p. 477), al referirse a las trepanaciones en esa misma área geográfica:

The operation was undertaken for the inmediate treatment of traumatic cranial injuries, and in certain areas its performance was extended to the treatment of severe headhache and others ailments, and as a prophylactic measure in children, against the occurence of such affections in subsequent life.

Para Weiss, en el Perú las trepanaciones experimentaron la misma generalización viciosa, si bien eligiendo un sitio distinto de la anatomía cefálica: las trepanaciones profilácticas en Oceanía se hacían labrando surcos profundos en la frente en tanto que en América, hasta donde se sabe, se efectuaban sobre la nuca. ${ }^{3}$

A los elementos mencionados hasta este momento para interpretar el significado de la lesión suprainiana, podemos agregar un dato más, de especial importancia para Mesoamérica, obtenido de uno de los cronistas del siglo xvi. Al referirse a la práctica de la deformación intencional de la cabeza, Landa (1966, p. 54) proporciona un dato de gran interés, ya que podría confirmar la naturaleza cultural, posiblemente ritual, de la lesión suprainiana. Dice textualmente:

3 En su documentada obra sobre la trepanación peruana, Lastres y Cabieses (1960, pp. 162-63), reconocen las características peculiares de la lesión suprainiana, sin pronunciarse no obstante por la interpretación de Weiss. 
... a los cuatro o cinco días de nacida la criaturita poníanla tendidita en un lecho pequeño, hecho de varillas, y allí, boca abajo, le ponían entre dos tablillas la cabeza: la una en el colodrillo y la otra en la frente entre las cuales se le apretaban tan reciamente y la tenían allí padeciendo hasta que acabados algunos días les quedaba la cabeza llana y enmoldada como la usaban todos ellos. Era tanta la molestia y el peligro de los pobres niños, que algunos peligraban, $y$ el autor vio agujerearle a uno la cabeza por detrás de las orejas, y asi debian bacer a muchos (cursivas nuestras).

Evidentemente, la deformación de la cabeza efectuada mediante la presión de tablillas no precisaba de ninguna perforación de los huesos de la cabeza, de manera que lo que para Landa fue un agujeramiento por detrás de las orejas quizás- haya sido una práctica diferente, que por su localización puede haberse tratado del raspado suprainiano, que en algunos casos llegaba a perforar el hueso occipital.

Esto no significa, por supuesto, que deba ignorarse la estrecha asociación que presenta en Mesoamérica la lesión suprainiana y la deformación craneal intencional. Todos los ejemplares que exhiben la lesión presentan también alteración intencional de la plástica craneana, lo cual no es de extrañar, sin embargo, en pueblos esencialmente deformadores, como los mesoamericanos. El elevado porcentaje de cráneos deformados comprueba la prevalencia de esta costumbre desde tiempos muy antiguos, en dicha área cultural. No obstante, es posible que exista una relación entre ambas prácticas aunque por el momento, el problema no pueda ser aclarado completamente.

Por otra parte, cuando se trata de identificar la lesión en cráneos de origen arqueológico, se presenta el problema de los casos en que la lesión está totalmente cicatrizada, de manera que no puede distinguirse con claridad algunas variantes morfológicas normales o de otra índole, del occipital. Debe reconocerse, por lo tanto, la necesidad de establecer un criterio que permita diferenciar los distintos fenómenos que pueden darse en un mismo sitio anatómico. Un estudio en tal sentido ha sido emprendido utlizando los materiales craneológicos que existen en el Museo Nacional de Antropología (comunicación personal del antropólogo Zaid Lagunas).

Aun con esta salvedad, y considerando sólo los casos en que la lesión suprainiana es bien evidente, debemos acreditarle su naturaleza de rasgo intencional, con valor semejante al de la deformación arti- 
ficial de la cabeza o de la mutilación e incrustación dentarias, a pesar de que la motivación que llevó a esa práctica, muy probablemente de tipo ritual, pueda aun ser discutida.

\section{Distribución de la lesión suprainiana en Mesoamérica}

Aceptar la implicación cultural de la lesión suprainiana le otorga un interés arqueológico indudable. En efecto, si la trepanación suprainiana es un rasgo étnico característico de algunas culturas peruanas, como lo ha probado Weiss, su presencia en otras áreas geográficas americanas le confiere necesariamente una importancia arqueológica que debe ser considerada. Ya el multicitado investigador peruano mencionaba el interés que revestiría el rastreo de la trepanación suprainiana en el territorio intermedio entre los dos grandes núcleos de civilizaciones americanas: "... si se encontrase en México la misma trepanación en niños y las variantes y formas frustras, que pueden haber pasado desapercibidas como en el Perú, se podría identificar como el mismo sistema, incrementando sus méritos como posible factor de difusión" (1958, p. 548). Los hallazgos de Cholula han materializado esta posibilidad (Lagunas, 1970): la lesión se presenta abundantemente con diversas intensidades y existen casos notables en cráneos infantiles.

Weiss mismo menciona en su obra un cráneo de Juchitán, Oaxaca que tuvo oportunidad de examinar en el Museo Nacional de Antropología de México. Posteriormente, el mismo investigador encuentra tres casos más en el Museo de Antropología de la ciudad de Guatemala (Weiss, 1967).

La identificación de la misma lesión en un cráneo más del área maya, en el esqueleto del entierro 1 de Palenque (temporada 1970 ), vino a confirmar la indicación que los otros hallazgos apuntaban, es decir, que esta característica tuvo una distribución amplia en Mesoamérica y que, a juzgar por los casos de Cholula, era bastante frecuente por lo menos en una época.

Estas consideraciones fueron un estímulo para examinar algunos ejemplares craneales de otras localidades arqueológicas de México, pertenecientes a las colecciones osteológicas del Museo Nacional de Antropología, ${ }^{4}$ para intentar localizar nuevos casos. No se trata, por

4 Agradecemos al profesor Arturo Romano, Jefe del Departamento de Antropología Física del INAH, el apoyo brindado para la realización de este trabajo. 
supuesto, de un examen exhaustivo, sino de un sondeo en algunas colecciones osteológicas: ampliar esta revisión a todos los sitios arqueológicos representados en los abundantes materiales óseos conservados en el Museo Nacional de Antropología es una investigación que debe realizarse.

Hasta el momento, los resultados obtenidos pueden resumirse como sigue (tabla I):

\section{TABLA I}

CRÁNEOS CON LESIÓN SUPRAINIANA EN MESOAMÉRICA. ALGUNOS CASOS IDENTIFICADOS

\begin{tabular}{|c|c|c|c|}
\hline Procedencia & $\begin{array}{l}\text { Núm. } \\
\text { de casos }\end{array}$ & $\begin{array}{c}\text { Periodo } \\
\text { arqueológico }\end{array}$ & $\begin{array}{l}\text { Referencia } \\
\text { bibliográfica }\end{array}$ \\
\hline Culhuacán, D. F. & 2 & Posclásico & $x$ \\
\hline Teopanzolco, Mor. & 3 & , & \\
\hline Cholula, Pue. & $15 *$ & $"$ & Lagunas, 1970 \\
\hline Lidchi Bigu, Juchitán, & & & \\
\hline Oax. & $4+$ & $"$ & Weiss, 1958 \\
\hline Zapotal, Ver. & $6 \ddagger$ & $"$ & \\
\hline Chichén Itzá, Yuc. & 4 & $"$ & Lagunas, 1970 \\
\hline Chinkultic, Chis. & 2 & $\eta$ & \\
\hline Palenque, Chis. & 1 & $"$ & \\
\hline Zaculeu y Tzicuay, & & & \\
\hline Guatemala & 3 & ? & Weiss, 1967 \\
\hline
\end{tabular}

* Hasta el momento, el número de casos es mucho mayor (comunicación personal de Z. Lagunas).

† Weiss se refiere al único ejemplar que examinó; en la pequeña serie de cráneos de este sitio, existen 3 más con la lesión.

‡ Los cráneos examinados pertenecen a una colección en proceso de estudio por el profesor Arturo Romano.

De acuerdo a estos datos, podemos dar por establecido que la trepanación suprainiana es un rasgo bastante difundido en Mesoamérica, tanto en el centro de México como en el área maya. En la figura 1 se han indicado los sitios mesoamericanos que han proporcionado ejemplos de lesión suprainiana, algunos de los cuales se muestran en las láminas II y III. Seguramente un estudio más amplio de material craneológico prehispánico de México aportará nuevos datos al respecto. 
Cabe llamar la atención sobre la cronología de los cráneos que presentan la lesión, en relación a la pregunta que surge sobre el probable sitio de Mesoamérica donde pudo haberse originado o a partir del cual se difundió. Podemos considerar como muy remoto un fenómeno de paralelismo en un carácter en que coinciden todos sus elementos; si, como pensamos, ha habido una difusión, ¿cuál ha sido el sentido de ésta?

Los casos mencionados corresponden al horizonte Posclásico, aunque el cráneo de Palenque descrito en este trabajo pueda ser un poco más temprano, lo que podría quizá indicar prioridad cronológica de la lesión suprainiana en el área maya. Sin embargo, no debe descartarse la posibilidad de que existan ejemplos quizás más antiguos, procedentes de otras regiones geográficas. Por el momento es preferible hablar de un carácter propio del horizonte Posclásico que comparten varias regiones culturales de México. Debemos hablar de contactos culturales más que de influencias mientras no se tengan más datos sobre la distribución temporal y espacial del rasgo.

En el caso de Chichén Itzá, donde se encuentra la lesión suprainiana, se le podría considerar como un nuevo elemento del grupo de caracteres rituales que comparte este sitio con el centro de México; junto con el sacrificio por arrancamiento del corazón, el culto fálico y la cremación (Ruz, 1971, p. 218). No podemos aún, sin embargo, prejuzgar sobre el sentido de la difusión en cuanto a este carácter en particular.

\section{La lesión suprainiana en América prebispánica}

En un marco geográfico más amplio, podemos considerar la trepanación suprainiana en relación al debatido problema de las posibilidades de contacto entre las varias civilizaciones aborígenes del Nuevo Mundo.

La lesión se presenta con abundancia en el Perú (figura 1), según los estudios de Weiss, quien cita, entre otras, las localidades de La Calera, en el Valle de Chancay, el Valle del Casma, los cementerios de "El Brujo", Chanchán, "Castillo El Tanque", Morro Solar, Puerto Chicama, Pacasmayo y Ancón (1958, p. 542-43). La abundancia de casos puede deberse, aunque sea en parte, al interés especial mostrado en la identificación de la lesión y a la cantidad de restos estudiados. De todas formas, es un hecho establecido que esta lesión es bastante característica de algunas culturas peruanas, principalmente de la Costa. 


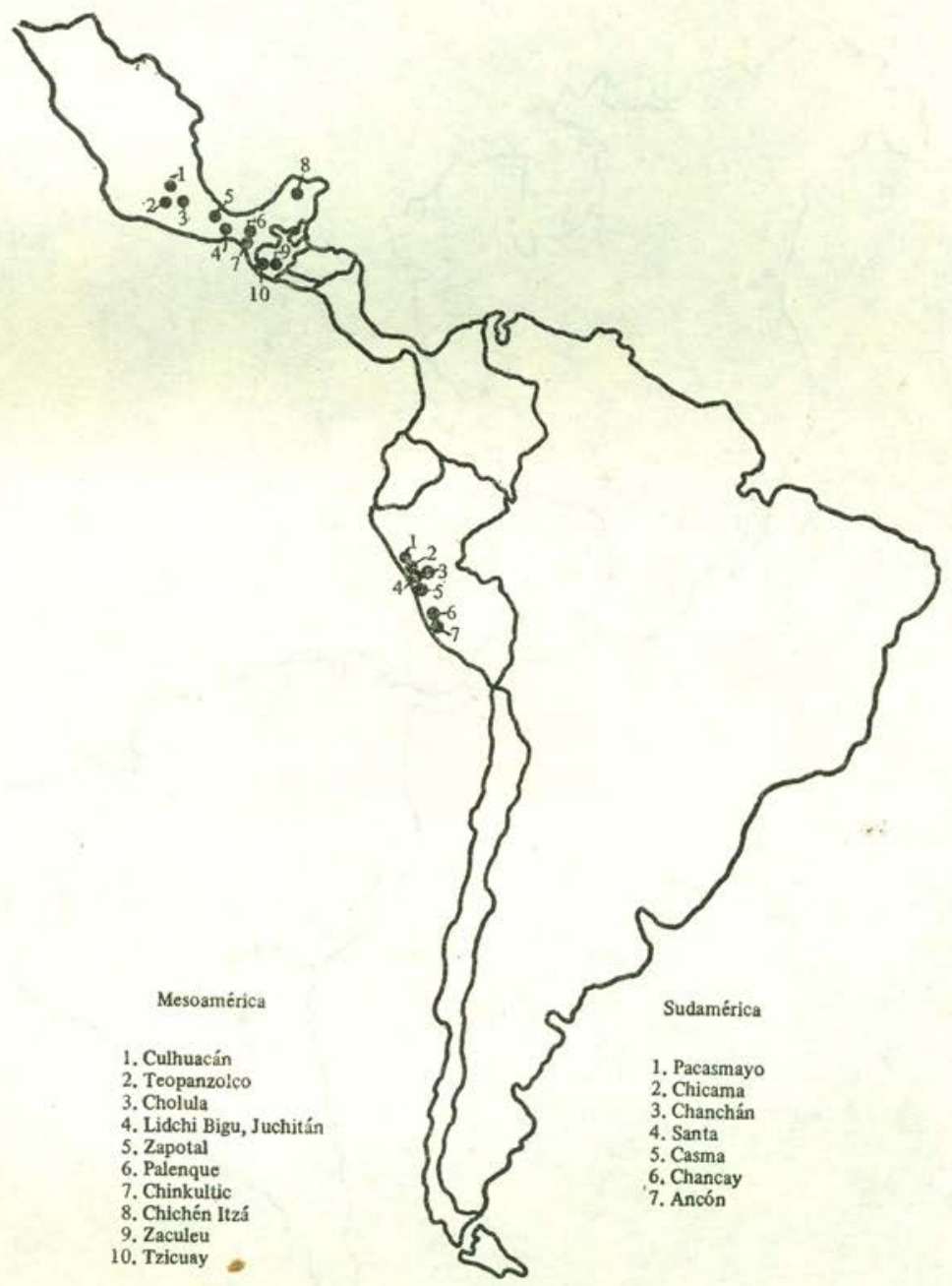

Figura 1. Distribución de la lesión suprainiana en América.

En cuanto a la cronología en esta área, parece restringirse al periodo tardío de la época prehispánica (Tiahuanaco costeño). Weiss considera que "En el Perú las manchas verdes en la cara, producidas por una placa de cobre que se acostumbraba poner en la boca de los muertos, la deformación por cuna, fronto-occipital o inca costeña y la trepanación ritual iniaca, forman un complejo que ubica con seguridad un cráneo en los periodos tardíos del litoral norte" (1958, pp. 15-16), si bien el mismo investigador indica en otra parte que 


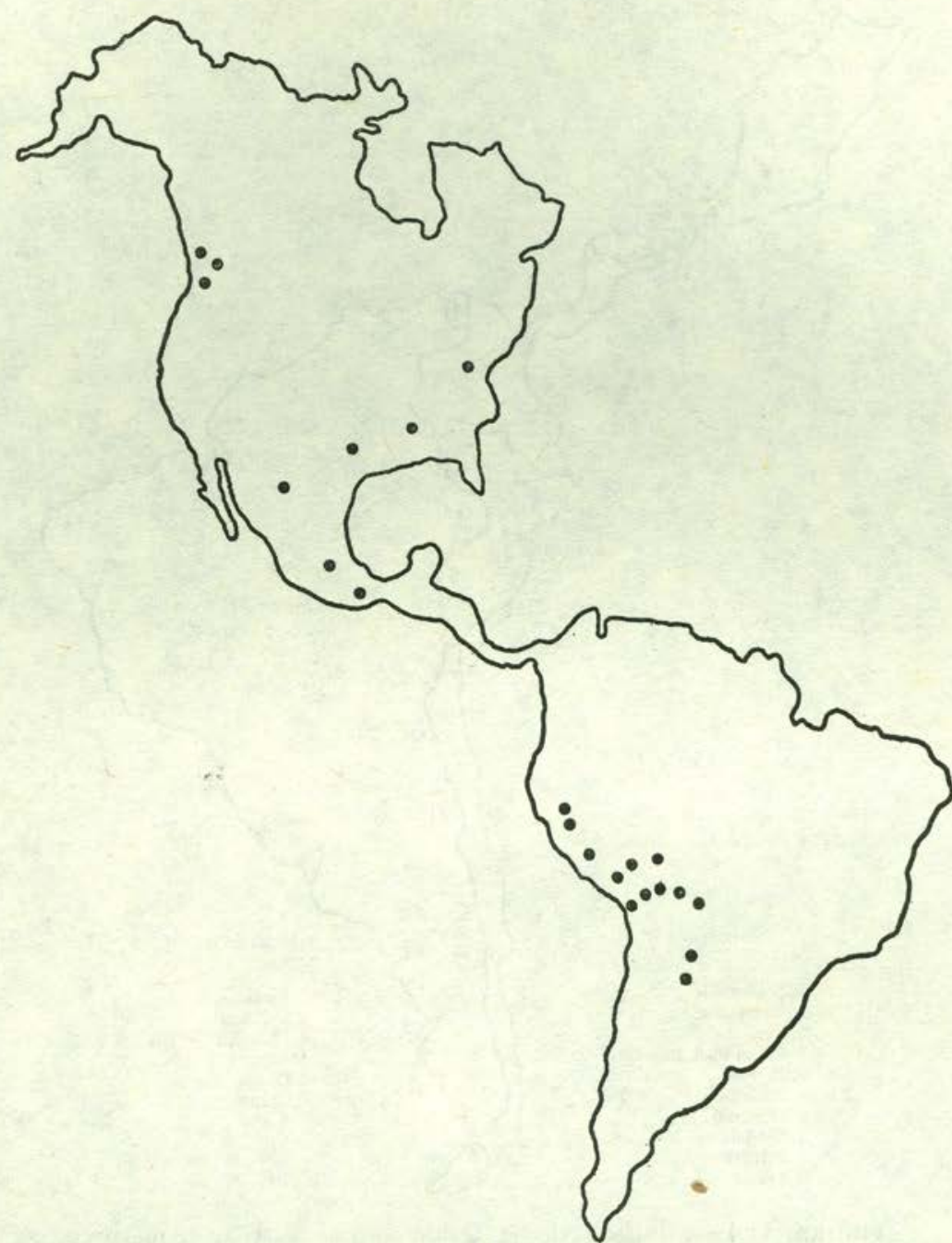

FIgURA 2. Distribución de la trepanación en América prehispánica. Según Palop, 1970 , p. 60.

"la trepanación suprainiana puede ser un rasgo arcaico y quizás andino, pero sólo se generaliza haciéndose fácilmente visible, al final del periodo medio de la Costa" (1958, p. 544).

Habiendo revisado someramente la distribución geográfica de la lesión suprainiana en América prehispánica, y si la consideramos como una práctica quirúrgica de naturaleza ritual, profiláctica, según la proposición de Weiss, tanto en Meso como en Sudamérica, po- 
demos preguntarnos ¿en cuál de ambas regiones geográficas ha tenido su origen? Como en general encontramos una equivalente cronológica en cuanto a su aparición en ambas regiones, no es posible por el momento inclinarse en uno u otro sentido, aunque se debe hacer notar que se carece de datos para gran parte de América Central y el área norte de Sudamérica, que podrían aportar alguna información al respecto.

Hasta ahora, quizás un elemento favorable para pensar en un origen sudamericano sería la profusión y variedades de las trepanaciones craneanas en general y el desarrollo de las técnicas respectivas que se encuentran en la región andina. Se han obtenido más cráneos trepanados en el Perú que en todo el resto del mundo en conjunto (Stewart, 1958, p. 473). En la figura 2 se muestra la distribución de las trepanaciones (excluyendo las suprainianas) en América prehispánica. La región andina no sólo posee un buen número de localidades que han provisto ejemplares trepanados, sino que el número de éstos es bastante elevado, alrededor de 1000 (Stewart, 1958, p. 473).

Por otra parte, si la trepanación con motivos terapéuticos ha precedido a la llamada trepanación ritual, la antigüedad en Sudamérica de esta práctica podría abonar también la opinión de que la lesión suprainiana es nativa de esa región americana. Aunque para Stewart (1958, p. 475), los cráneos trepanados más antiguos de Perú, los de Paracas (ca. s. V a C. - s. V d. C.) ${ }^{5}$ quizá "representan una fase del bien desarrollado culto de cabezas-trofeos más que una verdadera cirugía". "En otras partes del Perú la costumbre parece ser mucho más tardía, asociada aún con el ascenso de los Incas."

En cuanto a Mesoamérica y Norteamérica, las trepanaciones son mucho más escasas, aunque algunas bastantes antiguas. El foco principal de estas trepanaciones en que las trazas de traumatismo craneal apoya la idea de que la terapia fue una de las razones (Romero, 1970, p. 65), se encuentra en Monte Albán, Oaxaca. Hallamos allí una serie de ejemplares fechables entre 900 y 1000 d. C. (Clásico tardío), si bien el ejemplar de Monte Negro, Tilantongo, Oaxaca pertenece al Preclásico medio (900-600 a. C.), al igual que los tres cráneos perforados reportados por Faulhaber (1965), procedente de Tlatilco, México.

En opinión de Stewart (en Romero, 1970, p. 58), los especímenes de América Media considerados como trepanados son pocos e individualmente menos convincentes como ejemplos de cirugía deliberada

\footnotetext{
${ }^{5}$ Rytel (1962, cit. por Lisowski, 1967, p. 657), considera que la más antigua evidencia de trepanación en Perú data de ca. 3000 a. C.
} 
que la mayoría de los muchos hallazgos peruanos de esta naturaleza. El problema sería distinguir la verdadera cirugía craneal de las perforaciones craneales producidas de muchas otras maneras: heridas penetrantes sanadas, infecciones localizadas, perforaciones postmortem, etcétera, aunque debe reconocerse que algunos casos no pueden ser negados como práctica quirúrgica intencional.

En fin, aun cuando se reconozca que en América la región por excelencia de las trepanaciones es el Perú, la contemporaneidad de la lesión suprainiana en Meso y Sudamérica impide hablar de difusión a partir de una determinada región geográfica. Nuevamente podemos afirmar la existencia de contactos culturales, que eran obviamente posibles ya que no existen barreras infranqueables que separen ambas regiones. La lesión suprainiana puede considerarse como uno más de los numerosos rasgos que comparten los dos grandes núcleos de culturas avanzadas americanas.

Podemos concluir, con Ruz (1963, p. 35):

Es de esperarse que en un futuro no lejano se concrete la atención de los especialistas en esta meta tan transcendental [probar el contacto cultural entre ambas regiones] para la comprensión del origen y desarrollo de las altas culturas mesoamericanas. Creemos que cada nuevo descubrimiento tenderá a demostrar la unidad histórica de Meso y Sudamérica.

\section{Resumen}

El hallazgo de la llamada "lesión suprainiana" en el cráneo del entierro 1 de Palenque, Chiapas (temporada 1970), dio lugar a señalar la presencia en Mesoamérica de este rasgo cultural característico de algunas poblaciones prehispánicas del Perú. Se hace referencia a su amplia distribución mesoamericana, desde el centro de México hasta el área maya, señalando algunos nuevos sitios donde se le ha identificado.

La lesión suprainiana en México, como en el Perú, es un rasgo que aparece tardíamente en la cronología prehispánica, quedando sujeto a investigación su probable origen geográfico. Para aclarar este problema es preciso el estudio de nuevos materiales que permitan establecer las localidades donde se encuentra el carácter, su frecuencia y modalidades, así como el nivel cronológico en que se sitúan. El estudio de materiales centroamericanos y del área norte de Sudamérica sería de gran importancia a este respecto. 
Aun cuando no todos los casos de depresión suprainiana puedan ser considerados como intencionales, los que sí muestran elementos que permiten caracterizarlos como artificiales justifican la afirmación de la existencia de un rasgo cultural de interés arqueológico que merece ser estudiado en el contexto de las relaciones interhemisféricas de los principales centros de alta cultura de la América prehispánica.

\section{Addenda}

Estando en prensa este trabajo se han realizado algunas contribuciones sobre el mismo tema. T. D. Stewart (Amer. J. Phys. Antbrop., 35:296-97, 1971), encuentra la lesión suprainiana en cráneos de los indios Pueblo, y al comentar la distribución del carácter en América considera que se trata de un defecto debido no a cirugía sino a "irritación ósea y necrosis causada por presión del aparato deformador y prefiere llamarla "pseudotrepanación". Esta interpretación fue mantenida por el mismo autor más recientemente (XLI Cong. Intern. Americanistas, México, 1974).

Aun cuando pudiera existir una relación directa entre deformación tabular erecta y lesión suprainiana, como propone Stewart, la intervención quirúrgica está bien evidenciada en algunos ejemplares craneanos mexicanos, aunque es posible que estuviera condicionada por un necrosamiento del tejido óseo en el área afectada por la presión deformatoria (cf. Lagunas, Z., "Observaciones recientes sobre la lesión suprainiana", Boletín Inst. Nac. Antrop. Hist., México, en prensa). Pensamos que quizá sólo en las zonas de alta cultura se dio esta acción intencionada, que sería entonces de indole terapéutica; en este caso retendría igualmente su importancia como elemeńto cultural de posible difusión. Se trata, sin embargo, de un tema sujeto a investigación.

\section{BIBLIOGRAFIA}

ACKERKNECHT, E. H.

1967 "Primitive Surgery", en: Diseases in Antiquity, eds. D. Brothwell y A. T. Sandison, pp. 635-50. Charles C. Thomas Publisher. Springfield.

COMAS, J.

1966 Características físicas de la familia lingüistica maya. Cuadernos del Instituto de Investigaciones Históricas, serie antropológica, núm. 20. UNAM.

FAULHABER, J.

1965 "La población de Tlatilco, México, Caracterizada por sus Entierros", en: Homenaje a Juan Comas, vol. 2, pp. 83-121. México.

FORD, E.

1937 "Trephining in Melanesia", Med. Journal Australia, 2: 471-77.

LAgUNAS, Z.

1970 "Nota Sobre el Hallazgo de Cráneos con Lesión Suprainiana en Cholula", Boletin del Inst. Nal. de Antrop. e Hist., núm. 39, pp. 1-4. México. 
LANDA, Fr. Diego de

1966 Relación de las Cosas de Yucatán. Editorial Porrúa, S. A. México.

LISOWSKI, E. P.

1967 "Prehistoric and Early Historic Trepanation", en: Diseases in Antiquity, eds. D. Brothwell y A. T. Sandison, pp. 651-72. Charles C. Thomas Publisher. Springfield.

PALOP MARTíneZ, J.

1970 "Distribución Mundial de la Trepanación Prehistórica", Rev. Españ. Antrop. Amer., 5: 51-66.

PARKINSON, R.

1907 Dreissig Jahre in der Südsee. Stuttgart.

RYTEL, M. M.

1962 "Trephinations in Ancient Peru", Bull. Pol. Med. Sci. Hist., 5: 42.

ROMERO, J.

1970 "Dental Mutilation, Trephination, and Cranial Deformation", Handbook of Middle American Indians, Physical Anthropology, 9: $50-67$.

RuZ, A.

1963 La civilización de los antiguos mayas. Inst. Nal. Antrop. Hist., serie investigaciones, núm. 10. México.

1971 "Influencias Mexicanas Sobre los Mayas", en: Desarrollo Cultural de los Mayas, eds. E. Z. Vogt y A. Ruz, pp. 203-41. Coordinación de Humanidades, Centro de Estudios Mayas. UNAM.

STEWART, T. D.

1958 "Stone Age Surgery: a General Review with Emphasis in the New World", Annual Report of the Board of Regents of the Smithsonian Institution for 1957, pp. 469-91, Washington.

WEISS, P.

1958 Osteologia Cultural, Prácticas Cefálicas (1a. parte. Cabezas-trofeo, trepanaciones, cauterizaciones). Universidad Mayor de San Marcos. Lima.

1967 "Ensayo de Osteología Cultural en Guatemala". Antropología e Historia de Guatemala, 19 (1): 14-26. 


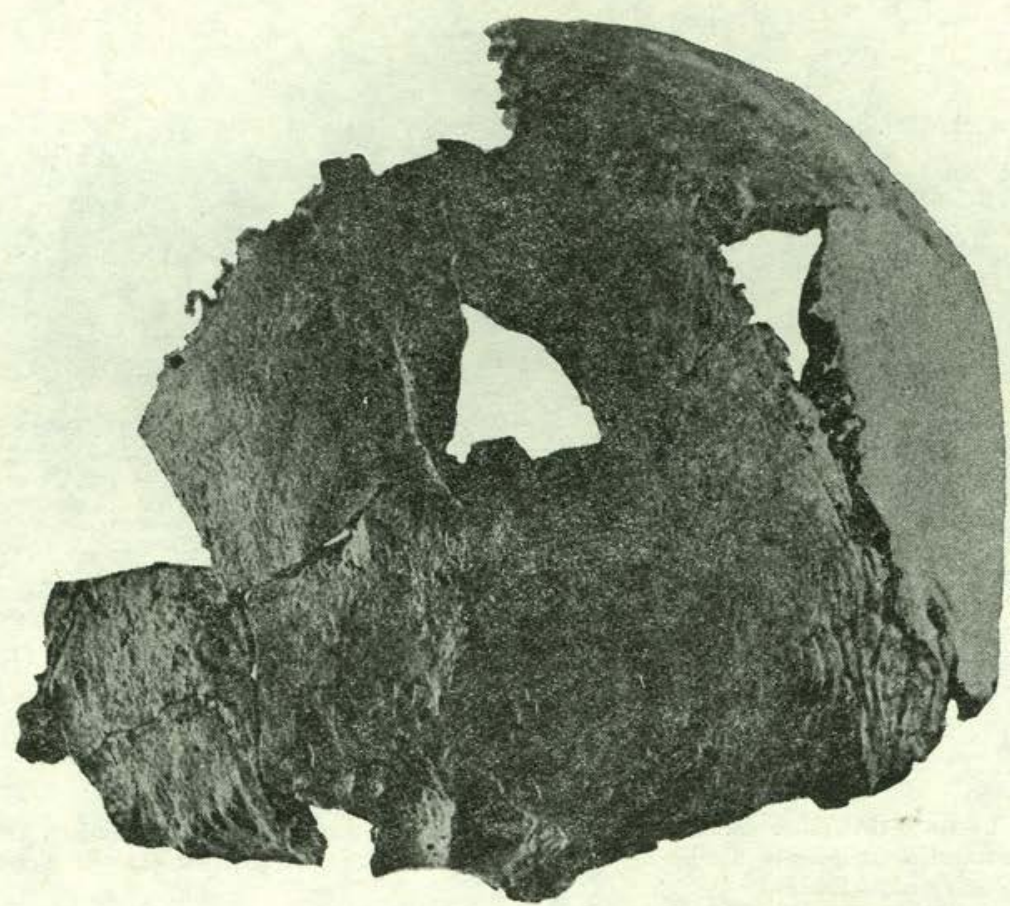

Lámina I. Lesión suprainiana en el cráneo del Ent. núm. 1 de Palenque, Chis. (temporada 1970). Se observa regeneración ósea en el área afectada por la lesión, a pesar de la rotura posmortem. (Fototeca Departamento de Antropología física, INAH.)

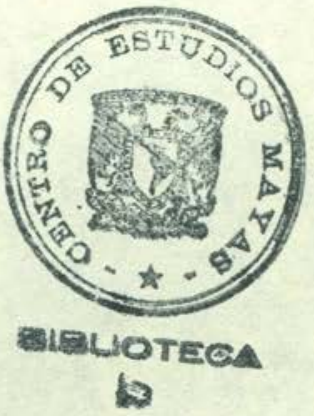




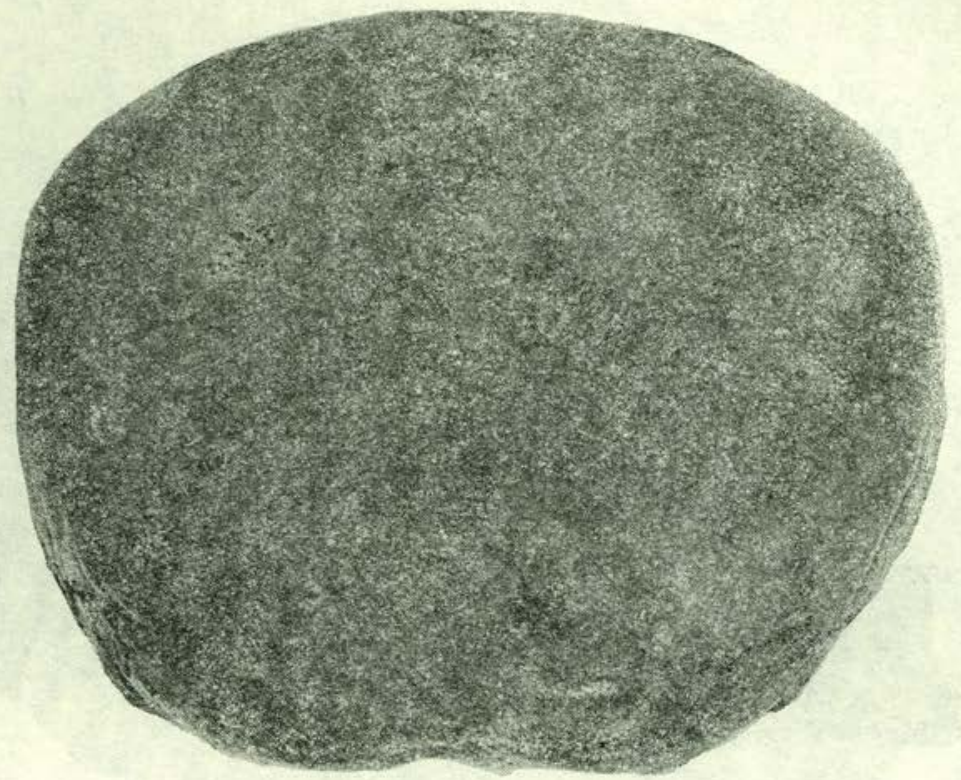

LÁMINA II. Cránéo infantil de Chichén Itzá, Yuc.; presenta lesión suprainiana con perforación completa y huellas de regeneración ósea. (Fototeca Departamento de Antro. pología física, INAH.) 


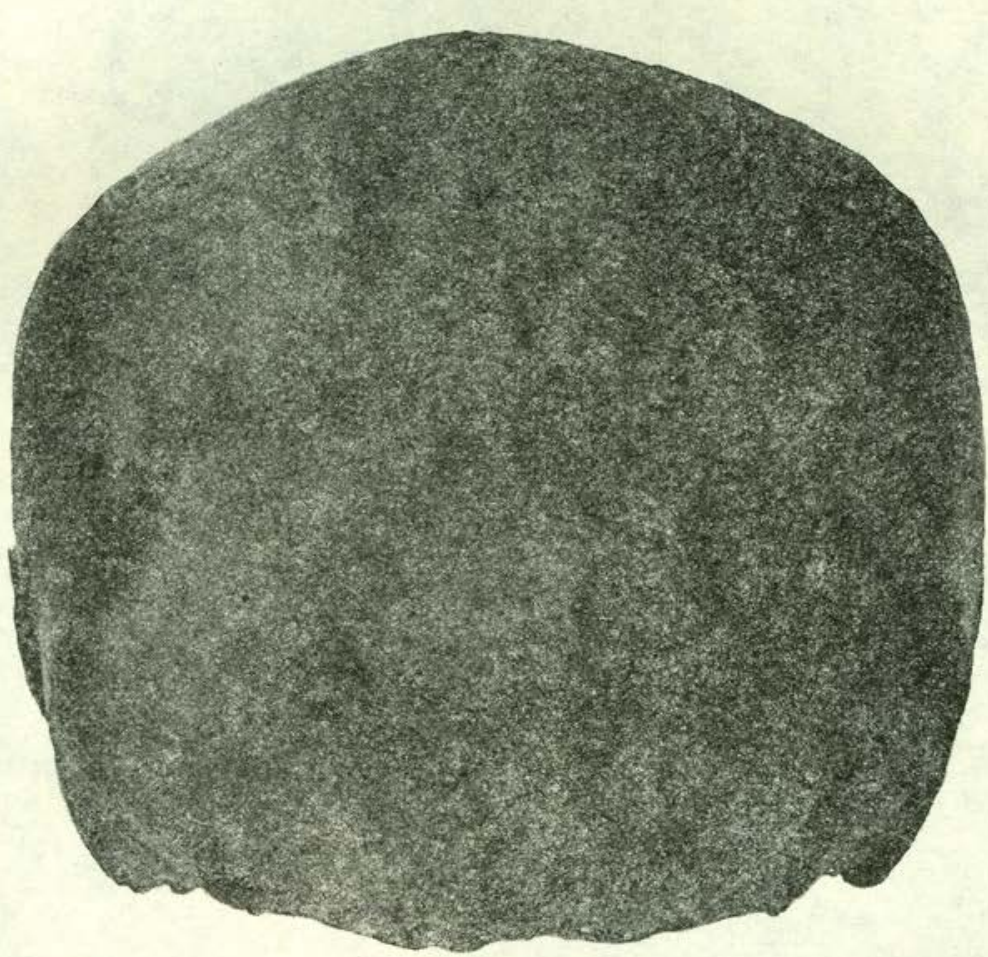

LÁMINA III. Cráneo procedente de Chinkultic, Chis. Obsérvese la bien marcada depresión suprainiana y la reacción ósea provocada por la lesión. (Fototeca Departamento de Antropología física, INAH.) 